\title{
The Impact of ICT Applications in the Development of Business Architecture of Enterprises
}

\author{
Abdullah AL-Malaise AL-Ghamdi' ${ }^{1}$, Farrukh Saleem² \\ Faculty of Computing and Information Technology \\ King Abdulaziz University, Jeddah, Kingdom of Saudi Arabia \\ Iaalmalaise@kau.edu.sa, ${ }^{2}$ fsaleem@kau.edu.sa
}

\begin{abstract}
Information and Communication Technology (ICT) considers a necessary element which create large impact on Business growth and development. The augmentation in technology means that it provides the ICT applications in such a way which boost up the business needs and provide integrated infrastructure for effective business transactions. Moreover, ICT applications are consistent enablers for the development of business architecture. In fact advance ICT applications integrate the business processes of the large business organizations and provide the fast information retrieval system from the integrated data stores. Importantly, this paper discusses about the terminology business architecture; functionalities and importance. Further, this paper elaborate several ICT applications and their impact on business architecture. Finally, the impact of ICT applications in the development of business architecture of enterprises presented with comprehensive analysis with the help of proposed framework.
\end{abstract}

Keywords : Architecture, Development, ICT Application

\section{INTRODUCTION}

Information and Communication Technology (ICT) has turned the organizations with massive robust business transactions throughout the globe. ICT domination is obvious evidence in business organizations by deploying the latest technologies and compete the marketplace by installing variety of IT applications to standardize and integrate their business processes. In the current era of competitive business strategies almost every small and medium enterprises (SMEs) have attracted their focus towards the IT integrated software packages. Modern technology has already shown its cheaper and affordable contributions towards building business architecture even more better way than before.

Eventually, every ICT investment; in the favor of new business process invention, fulfillment of strategic objectives, extra edge over organizational change and development from others will lead the enterprise on the top.

The role of ICT in the development of business architecture is important due to its vast and limitless applicability. This perspective highlights the enterprise's high dependency over ICT applications and even more complexity in evaluating the business benefits generated from those ICT applications [6, $18,33,34]$. The ICT in an organizations not only consisting on information systems and enterprise systems, rather it also considers a combination of several other resources such as computers, networks, communication tools, data transformation tools and etc. as discussed by [10]. Whether the purpose of those ICT resources is to support business processes to achieve the goals and objectives on which the business architecture has developed.

In the current business scenario, enterprises cannot afford the late response in deployment and updating new enhancement in ICT technology to stand their feet in the markets. Such as the rapid development in internet world, software packages with full of integration, hardware resources with high compatibilities solutions need to force enterprises to be updated their business resources. But sometimes enterprises are more focused on their product oriented processes and technologies [7] and they are late in responding to other technological issues. To meet with the current situation of the market they always need to reprocess their business process [8] due to its present requirement and better processing. Despite of these facts, it's even more complex to inline the business activities as per 
the requirements of ICT developments. As mentioned by [9], companies are more limited in responding towards the changing in their business processes due to lack of flexibility and adaptability. Furthermore, described by [11] the adaptation of ICT development within the strategic objectives is often slow and complex procedure. It happens as some ICT applications have high impact on business innovation but showing huge complexities in implementing and even future changes, for example Enterprise Systems [1]. As further illustrate by [13] several organization even not putting their full efforts in changing and updating the existing state of their enterprise systems to the current advancement in technology due to its vast complexities. Therefore, it has been noticed that 90 percent of enterprise system does not attain their desired goals for which they got implemented enterprise system, where one of the reason is its complex environment [14].

\section{FINDINGS AND DISCUSSION}

\subsection{Business Architecture}

The concept of business architecture is not new for the enterprises defined by different scholars and consultancy organizations [29, 30]. Organizations are doing businesses since they have established their product oriented, service oriented and eventually profit oriented processes to achieve their strategic objectives and to be a best competent in the market. Business architecture consider major part of enterprise architecture as shown in Figure-1[31]. It deals with business processes and modeling rather more with the technical and technological aspects. But eventually, as described in Figure-1, it incorporated with the technical infrastructure, data architecture, hardware and software of the business organization. Although business architecture is an essential part of enterprise architecture, but it doesn't apply that business architecture cannot fully operate completely alone [21]. It highlight the importance and applicability of business architecture that it purposefully work outside of the scope of enterprise architecture.

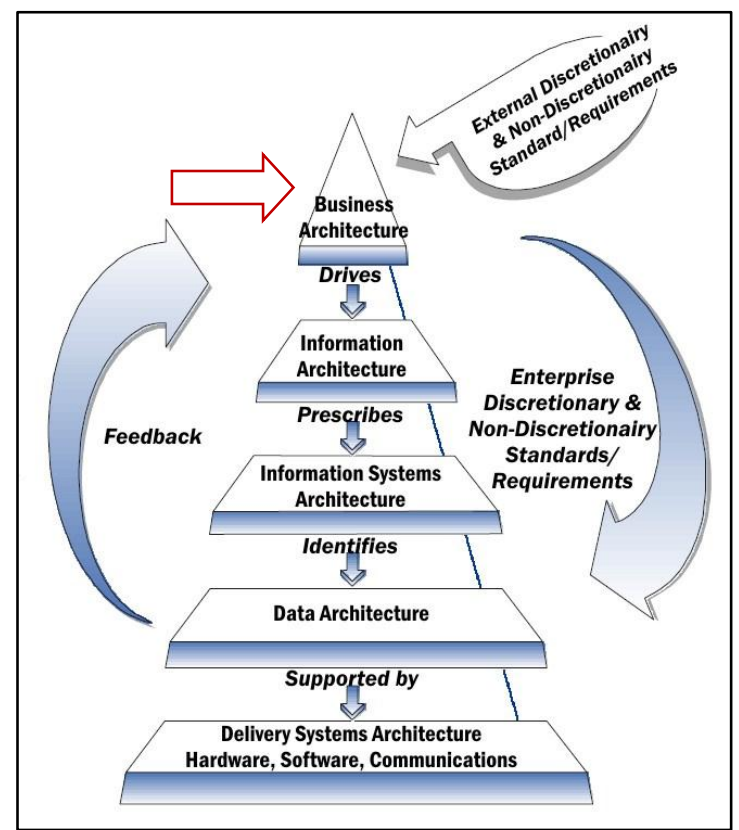

Fig1. NIST Enterprise Architecture Model, Described the place of Business Architecture [31]

Furthermore, business architecture is not only dealing with the internal processes of the organization. It is in between where business processes are running such as; marketing, production, distribution, etc. Therefore as considering to the information systems which deal with the individual business application's data and processes, business architecture has huge responsibilities to deal with all information systems and other application running in the enterprise for example, transport, wholesale and etc. [9]. As further discussed by [32] the implementation of business architecture is not specific to the internal dealing of the organization but it can also support and analyze the supply chain management and other external stakeholders connected with the organization to support their business goals.

Business architecture is the concept which is about to lead the organization in multiple ways. Understanding the core business processes and incorporate the business goals with strategic objectives are the main concerns of building business architecture. Greg Suddreth [19] explained five core 
principles of business architecture; (i) is about the business, (ii) is not perspective, (iii) is iterative, (iv) is reusable and (v) is not about the deliverables, which highlights the importance of it [19]. Business architecture is like a complete package which organize, support and implement the strategies to meet business goals as described by [20] that business architecture is a fundamental structure in a business organization which consists of business values, business models and business scenarios altogether to meet business objectives.

Organization presume to develop an actionable business architecture which consider to be beneficial for the organization in supporting business processes rather burdened on whole project. [21] proposed the methodology to create actionable business architecture by three perspectives; strategy and information, business process management, and service oriented architecture. The purpose of actionable plan is to create more accurate and fruitful environment to get more clear output. Several scholars has presented the concept of strongly association of business architecture with information and application architecture [22, 23, 24]. The purpose is business architecture has to support information and processes using several ICT applications. They supposed to connect with each other as mentioned by [31] that application architecture identifies data architecture which described by information architecture, where finally business architecture is on the top to drive all the processes and data in the organization. The major purpose of this paper is to support the idea of ICT application's impact on business architecture. In the same way, TOGAF defined business architecture which support mainly functional aspects of the business such as; business strategy, governance, organization and key business processes [25], where ICT application are there to support in defining strategy and govern key business processes.

\subsection{ICT Applications}

Nowadays, ICT applications are one of the major requirements to develop any business architecture. Enterprise needs major support of ICT architecture to achieve their targets. Although, the major goal of the organization is to support all business processes with the best of the resources to get the results faster than before and to compete in the market. This paper discuss about the ICT applications impact over business architecture. [21] has defined their relationship as shown in Figure-2, which highlights the connectivity enterprise in three ways such as; Strategy Model, Operating Model, and finally IT model. Whether the organization is dealing with the operation management or strategic management, the ICT applications are there to support their investments as well as initiative. The successful implementation of business architecture is undone without ICT applications and supporting architecture.

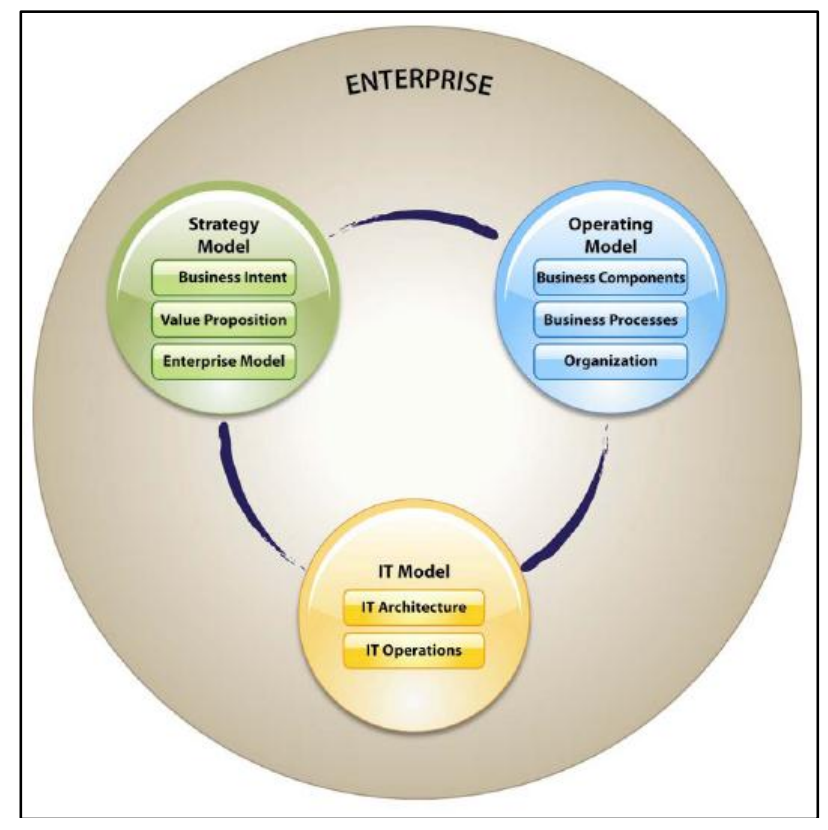

Fig2. Business Architecture and IT Model [21]

ICT application support the main strategies to accomplish the objectives and goals of the organization. There are many applications to support the business architecture, such as Enterprise Resource Planning (ERP) which is also known as Enterprise Systems (ES) software packages, which aim to 
integrate the entire processes in such ways to embody an absolute scenario of the business from a single information and ICT architecture [1,26]. Moreover, contribution to the world of business from these packages is remarkable and through this contribution the business has provided with efficient information from time to time they need it [1,2]. Enterprise applications has shown good support for creating efficient business environment, and has also been modified in different ways [28]. Similarly Decision Support System (DSS) has an important role in the development of successful business architecture [27]. DSS supports effective decision making in complex problems as well as provide strategic information development for activities such as production forecasting, well planned inventory control system, scheduling of activities, and effective communication for strategic planning [3] in the development of business enterprises. ERP and DSS are playing key roles in the development of business enterprises architecture. Although DSS and ERP both focuses on development, execution and adoption [4] but if it is requires then ERP aim to integrate and standardize the business processes and use to utilize these processes for supplying of materials as well as production and distribution of goods and services in organization [3,4]. (MISDOLEA, 2010) argued that with the development of economic scenario specially in diversification and globalization of global marketplace the companies are facing challenging issues for which the strategic decision making is also complex. Further stated that in such critical and challenging situation the companies are required to conceive innovative information systems to leverage with all these issues (MISDOLEA, 2010).

Another ICT application which associate closely with business architecture is known as Customer Relationship Management (CRM) [15, 17]. It support all processes related with customer dealing with the organizational internal sections. CRM and ERP association has been proposed by [16] which highlights the connection of both ICT application with the business integration.

The ICT architecture is not limited to the information systems and ERP application, it also support other software, hardware and specifically network and database application as discussed by [31]. This section highlights the importance and impact of ICT applications in developing successful business architecture. In the next section we discuss in more detail about their connection with the help of proposed framework in Figure-3.

\section{THE IMPACT OF ICT APPLICATION IN BUSINESS ENTERPRISE DEVELOPMENT: PROPOSED FRAMEWORK}

Above discussion highlights the importance of ICT and business architecture in different perspectives. It shows ICT and business architecture are dependent on each other in order to maintain business growth and ultimately achieve goals and benefits out of it. There are some consequences where sometimes it easy to adopt with new ICT advancements and somewhere due to its complex implementation [11] it need proper timely planning. It requires proper ways to handle in this situation to understand the elements of ICT and its implementation in support of business processes. As briefly described by [12] through asking six basic questions while changing and implementing IT within the enterprise, while two questions out of them are:

a. What are the implications of IT in my business operations? Today? In Future.

b. What are the alternatives perspectives for leveraging information technology capabilities for business operations?

By implementing the above strategies to find out the answers of these question will help and guide them the implementation of new ICT resources, as well as, the answers of how and in what ways it can provide some or major benefits to the enterprise. Furthermore, it will also help to identify, how it will change or improve the business architecture from the current scenario to the future development.

This research highlights the high importance and impact of ICT application over business architecture. Although business architecture, support business strategies, models and processes but the support and their link together through ICT architecture is more important. The proposed framework as well highlights the standing of business architecture in the middle while its communicating to all of the essential elements required in the organization such as; dealing with different types of stakeholders, business modeling, strategic development, information systems applications and others. To create a specific business architecture all supporting factors are important to work properly. While the major perspective of the organization is also to deal with strategic objectives and goals achievement. Timely enhancement of technology based on the current requirements of the market, 
installing the best ICT resources and their proper working can provide feasible results to accomplish the business goals, which will finally enhance the credibility of business architecture in enterprises.

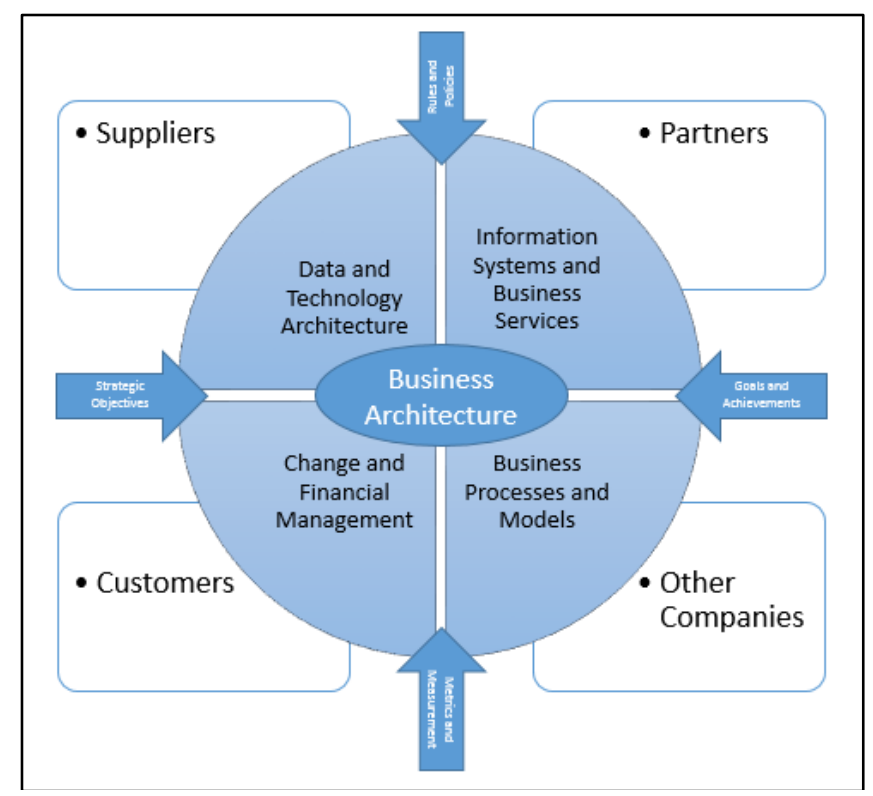

Fig3. A Proposed Integrated Framework of ICT Applications and Business Architecture

\section{CONCLUSION}

This paper investigates the importance and impact of ICT applications in the development of enterprise business architecture. The discussion of ICT application and business architecture from different scholar's perspectives highlight the issue, that proper planning of strategies is more dependent on timely enhancement of the technology. To provide successful implementation of business architecture and ICT applications, ultimately make the enterprises and their projects successful. Proposed framework presented in this research which further extends the concept of business architecture's dealing is not with the internal processes and business models of the organization but it also support the external stakeholders such as; suppliers and partners. Therefore, it further support the idea of business architecture dependency on ICT based applications. This research will further improve the proposed framework through expert opinion from the field of business architecture and ICT experts as well. This strategy can enhance the model in more specific manner where it can also provide the list of dimensions and sub-dimensions for building and measuring business architecture.

\section{REFERENCES}

[1] Al-Mudimigh, AS. (2007), the role and impact of business process management in enterprise systems implementation, Business Process Management Journal, Vol. 13 No. 6, pp 866-874.

[2] Sandoe, K., Corbitt, G. and Boykin, R. (2001), Enterprise Integration, Wiley, New York, NY.

[3] ITTIPHAISITPAN, R. (2011), A COMPARISON OF DECISION SUPPORT AND ENTERPRISE RESOURCE PLANNING SYSTEMS: THE VIEWS OF IT AND NON IT PROFESSIONALS, Journal of Information Technology Management, Volume XXII, Number 4, pp 13-46.

[4] Arnold, JR., and Tony. (1998), Introduction to Materials Management (3rd edition), Upper Saddle River, Prentice Hall, New Jersey.

[5] MISDOLEA, R. (2010), Decision Support System and Customer Relationship Management as Components of the Cybernetic System Enterprise, Informatica Economică vol. 14, no. 1, pp 201207.

[6] Farrukh Saleem, Naomie Salim, Abdullah AL-Malaise AL-Ghamdi and Zahid Ullah (2015), Building Framework for ICT Investments Evaluation: Value on Investment Perspective, ARPN Journal of Engineering and Applied Sciences, Vol. 10, No. 3, February 2015.

[7] Van Diepen, T. (2000). Multi-Channel Distribution in Financial Services. Impact of Electronic Distribution Channels on the Internal Organization. TIC-AMSTERDAM-, 6, 37-60. 
[8] Hammer, M., \& Champy, J. (2009). Reengineering the Corporation: Manifesto for Business Revolution, A. Zondervan.

[9] Versteeg, G., \&Bouwman, H. (2006). Business architecture: A new paradigm to relate business strategy to ICT. Information Systems Frontiers, 8(2), 91-102.

[10] Saleem, F., Salim, N., Fayoumi, A. G., Al-Ghamdi, A. S., \& Ullah, Z. (2013). Comprehensive Study of Information and Communication Technology Investments: A Case Study of Saudi Arabia. International Information Institute (Tokyo). Information, 16(11), 7875.

[11] Rijsenbrij, D., Truijens, O., \&Goedvolk, H. (2000). Redefining business: IT alignment through a unified framework (pp. 3-19). Universiteit van Amsterdam, Department of Accountancy \& Information Management.

[12] Henderson, J. C., \& Venkatraman, N. (1993). Strategic alignment: Leveraging information technology for transforming organizations. IBM systems journal,32(1), 4-16.

[13] Barnes, M. (1999). Customization of ERP apps requires development skills. Information Weel, February.

[14] Martin, M. H. (1998). An ERP strategy, Fortune, Vol. 2., pp. 149-151

[15] Al-Mudimigh, A. S., Ullah, Z., \& Saleem, F. (2009, May). Data mining strategies and techniques for CRM systems. In System of Systems Engineering, 2009. SoSE 2009. IEEE International Conference on (pp. 1-5). IEEE.

[16] Al-Mudimigh, A. S., Saleem, F., \&Ullah, Z. (2009). The Role Of Data Mining In ERP-CRM Model.

[17] Al-Mudimigh, A. S., Ullah, Z., \&Saleem, F. (2011). Successful implementation of CRM: The role of data mining. In International Conference on Computer Engineering and Applications IPCSIT (Vol. 2, pp. 424-429).

[18] Farrukh Saleem, Naomie Salim, Ayman G. Fayoumi,Abdullah Alghamdi (2012), A General Framework for Measuring Information and Communication Technology Investment: Case Study of Kingdom of Saudi Arabia, Advanced Machine Learning Technologies and Applications Volume 322 of the series Communications in Computer and Information Science pp 474-486

[19] Greg Suddreth and Whynde Melaragno (2010), Five Core Principles of Successful Business Architecture, Strategic Technology Architects, MEGA.

[20] Kishida, T., Aoyama, M., \& Kikushima, Y. A Goal-Oriented Design Methodology of IT-Driven Business Architecture.

[21] Harishankar, R., \& Daley, S. K. (2011, September). Actionable business architecture. In Commerce and Enterprise Computing (CEC), 2011 IEEE 13th Conference on (pp. 318-324). IEEE.

[22] BWAG, "Business architecture working group," http://bawg.omg.org/.

[23] D. Mc David, "A standard for business architecture description," IBM Systems Journal, vol. 38, pp. 12-31, 1999.

[24] G. Versteeg and H. Bouwman, "Business architecture: A new paradigm to relate business strategy to ict," Information Systems Frontiers, vol. 8, p. 91102, 2006.

[25] Open Group, "The open group architecture framework (togaf) version 8.1.1, enterpise edition," April 2007, http//www.opengroup.org/.

[26] Al-Mudimigh, A. S., Saleem, F., \& Ullah, Z. (2009, May). The Effects of Data Mining in ERPCRM Model- A Case Study of Madar. In S. Chen (Ed.), WSEAS International Conference. Proceedings. Mathematics and Computers in Science and Engineering (No. 8). World Scientific and Engineering Academy and Society.

[27] Saleem, F., \& Al-Malaise, A. S. (2012, June). Implementation of data mining approach for building automated decision support systems. In Information Society (i-Society), 2012 International Conference on (pp. 127-130). IEEE.

[28] Al-Malaise Al-Ghamdi, A., \& Saleem, F. (2014, August). Enterprise application integration as a middleware: Modification in data \& process layer. In Science and Information Conference (SAI), 2014 (pp. 698-701). IEEE. 
The Impact of ICT Applications in the Development of Business Architecture of Enterprises

[29] Zachman, J. (1987). A framework for information systems architecture. IBM systems journal, 26(3), 276-292.

[30] ISO 15704. Industrial automation system-requirements for enterprise reference architectures and methodologies 1999.

[31] Chief Information Officer Council (2001) A Practical Guide to Federal Enterprise Architecture Version 1.0 Preface. February 2001.

[32] Chandra, C., \& Kumar, S. (2001). Enterprise architectural framework for supply-chain integration. Industrial Management \& Data Systems, 101(6), 290-304.

[33] Saleem, F., Salim, N., Fayoumi, A. G., Al-Ghamdi, A. S., \& Ullah, Z. (2013). Comprehensive Study of Information and Communication Technology Investments: A Case Study of Saudi Arabia. International Information Institute (Tokyo). Information, 16(11), 7875.

[34] Saleem. F., Salim. N., Al-Malaise, A. Sand UllahZ. (2015), Building Framework for ICT Investments Evaluation: Value on Investment Perspective, ARPN Journal of Engineering and Applied Sciences, Vol. 10, No. 3. 